\title{
Preface to special issue on numerical modelling of URM buildings: benchmark project
}

\author{
Mauro Dolce ${ }^{1} \cdot$ Sergio Lagomarsino ${ }^{2} \cdot$ Humberto Varum $^{3}$
}

Accepted: 31 January 2022 / Published online: 24 February 2022

(c) The Author(s) 2022

Keywords Existing URM buildings · Modelling strategies · Nonlinear analysis · Benchmark structures $\cdot$ Software packages

The seismic safety assessment of existing unreinforced masonry (URM) structures requires careful modeling of the building and adequate ability to analyze it in the non-linear domain, while the use of the linear static analysis may be problematic, due to the difficulty of identifying the behavior and over-strength factors on a simply typological basis. In fact, the maximum strength of the structural elements and components may occur for different horizontal demands and, therefore, it may be difficult to identify a-priori the seismic collapse mechanism and the ultimate displacement capacity. Indeed, one of the mandates of the ongoing revision of the Eurocode 8 (Design of structures for earthquake resistance), namely of the Part 3 (Assessment and retrofitting of buildings and bridges), is to foster the use of nonlinear modelling (Bisch 2018).

The earthquakes that hit the European countries in the recent past, in particular Italy, have confirmed the high vulnerability of the masonry buildings heritage. For its reduction, it is therefore necessary to strengthen these buildings according to well-calibrated seismic design projects, which should be based on a rigorous overall understanding of their complex seismic behavior and considering exhaustively all variables involved through adequately accurate numerical analyses.

However, the high potential of the available numerical tools often leads the designer to adopt complex models, with a very accurate numerical representation of the geometry of building structural elements. This can give a false impression of accuracy of the numerical

Sergio Lagomarsino

sergio.lagomarsino@unige.it

Mauro Dolce

Mauro.Dolce@protezionecivile.it

Humberto Varum

hvarum@fe.up.pt

1 University of Naples Federico II, Via Claudio 21, 80125 Naples, Italy

2 Department of Civil, Chemical and Environmental Engineering, University of Genoa, Via Montallegro 1, 16145 Genoa, Italy

3 CONSTRUCT-LESE, Civil Engineering Department, Faculty of Engineering, University of Porto, Rua Dr. Roberto Frias, 4200-465 Porto, Portugal 
results in reproducing the seismic behavior of masonry building structures, while it may strongly depend on some peculiar and detailed aspects of the mechanical properties, parameters and modeling approaches.

Moreover, instead of adopting general purpose software packages, in the engineering practice it is observed an extensive use of customized computer programs, which make the process easier and faster but may lead designers to disregard even the basic assumptions made by the program's developer, favoring their possible improper use. Indeed, these software packages often propose predefined modeling methods, which can lead the designer not to carefully evaluate whether these hypotheses are able to realistically reproduce the behavior of the specific building under consideration.

For these reasons, it is particularly important that, whether using general purpose finite element programs or special customized programs, the designer is aware of the modeling choices automatically adopted by the program, and, allowing to adjust the available modelling options that better reproduce the behavior of the building under consideration.

The Italian Department of Civil Protection, as part of its prevention activities, since 2004 has been promoting and funding experimental, theoretical and numerical studies on the seismic risk and its reduction. This activity has fostered a long process of knowledge development and accumulation of experiences in the Italian scientific community, within the ReLUIS Consortium (Network of University Laboratories of Seismic and Structural Engineering), Competence Center of the Department of Civil Protection. One of the tasks, coordinated by Serena Cattari and Guido Magenes, was dedicated to "URM nonlinear modelling - Benchmark project", whose main results are collected in this special issue (SI). The main goal of the project was to provide reference solutions of relevant and representative case studies, useful to the engineering community, based on nonlinear analysis of masonry buildings with different common modeling approaches and software tools.

To this aim, a set of benchmark structures was conceived, adopted as reference, to verify and validate the reliability of software packages commonly used by professionals and researchers for the nonlinear modelling and seismic assessment of URM buildings.

In the first paper of the SI (Cattari and Magenes 2021), the whole set of proposed benchmark study cases is illustrated, together with the standardized criteria adopted to compare the results. The study cases are characterized by increasing complexity, ranging from simple panels to 3D structures representative of actual buildings. These benchmarks can also be replicated by other researchers and civil engineers since all the input data are provided as supplementary electronic material. This constitutes one of the valuable outcomes of the "URM nonlinear modelling - Benchmark project".

The second paper of the SI (Cattari et al. 2021) provides a comprehensive review of the critical issues on nonlinear modeling for evaluating the seismic response of masonry structures, emphasizing the ones relevant to engineering practice. Various modelling strategies are covered in the paper, ranging from the Equivalent Frame approach (widely used in the engineering practice) to refined techniques like 2D and 3D Finite Element procedures based on continuous, discrete, and micro-mechanical approaches. Relevant challenging issues concerning the use of numerical models in seismic assessment with the nonlinear static approach are also presented and discussed.

The third paper of the SI (D'Altri et al. 2021) goes insight the issue on the calibration of mechanical parameters addressed to guarantee, as much as possible, a cross-consistency among different modelling approaches. Indeed, this often constitutes one of the primary sources of scattering in the results. In the paper, five different models are explored. 
Then, the following six papers illustrate the results achieved by the research group on the benchmark study cases. The common feature of all these papers is presenting comparative results of various models, developed as much as possible by adopting the same assumptions. Then, the possible differences in the results obtained by the different software packages are interpreted in detail, namely providing an estimate of the intrinsic epistemic modelling uncertainties; this is an additional valuable outcome of the research.

In Manzini et al (2021) and Cannizzaro et al (2021), a 3D model of a 2-storey single unit URM building is analysed by comparing different equivalent frame models, as well as several strategies based on two and three dimensional (finite and discrete) elements, respectively.

The following three papers are based on 3D complex configurations, inspired by real existing buildings. Ottonelli et al (2021) and Castellazzi et al. (2021) analyse a benchmark building based on the P. Capuzi school in Visso, while Degli Abbati et al. (2021) examines a building inspired by the Pizzoli town hall. These buildings are very interesting being permanently monitored by the Italian Department of Civil Protection and having been hit by the Central Italy 2016-2017 earthquake. Thus, these benchmark structures provide interesting data to be used also for checking the reliability: of the numerical damage against the observed damage, for the former one; of the estimated dynamic properties in comparison with the results from Ambient Vibration Tests, for the latter.

Finally, in Occhipinti et al. (2021) the comparative study on a 2D multi storey wall is illustrated by focusing on the use of finite and discrete element models.

Open Access This article is licensed under a Creative Commons Attribution 4.0 International License, which permits use, sharing, adaptation, distribution and reproduction in any medium or format, as long as you give appropriate credit to the original author(s) and the source, provide a link to the Creative Commons licence, and indicate if changes were made. The images or other third party material in this article are included in the article's Creative Commons licence, unless indicated otherwise in a credit line to the material. If material is not included in the article's Creative Commons licence and your intended use is not permitted by statutory regulation or exceeds the permitted use, you will need to obtain permission directly from the copyright holder. To view a copy of this licence, visit http://creativecommons.org/licenses/by/4.0/.

\section{References}

Bisch P (2018) Eurocode 8. Evolution or revolution. In: Pitilakis K (ed) Recent advances in earthquake engineering in Europe. Springer, Cham, pp 639-660

Cannizzaro F, Castellazzi G, Grillanda N et al (2021) Modelling the nonlinear static response of a 2-storey URM benchmark case study: comparison among different modelling strategies using two- and threedimensional elements. Bull Earthq Eng. https://doi.org/10.1007/s10518-021-01183-0

Castellazzi G, Pantò B, Occhipinti G et al (2021) A comparative study on a complex URM building: part II-issues on modelling and seismic analysis through continuum and discrete-macroelement models. Bull Earthq Eng. https://doi.org/10.1007/s10518-021-01147-4

Cattari S, Magenes G (2021) Benchmarking the software packages to model and assess the seismic response of unreinforced masonry existing buildings through nonlinear static analyses. Bull Earthq Eng. https:// doi.org/10.1007/s10518-021-01078-0

Cattari S, Calderoni B, Caliò I et al (2021) Nonlinear modeling of the seismic response of masonry structures: critical review and open issues towards engineering practice. Bull Earthq Eng. https://doi.org/10. 1007/s10518-021-01263-1

D'Altri AM, Cannizzaro F, Petracca M et al (2021) Nonlinear modelling of the seismic response of masonry structures: calibration strategies. Bull Earthq Eng. https://doi.org/10.1007/s10518-021-01104-1 
DegliAbbati S, Morandi P, Cattari S et al (2021) On the reliability of the equivalent frame models: the case study of the permanently monitored Pizzoli's town hall. Bull Earthq Eng. https://doi.org/10.1007/ s10518-021-01145-6

Manzini CF, Ottonelli D, DegliAbbati S et al (2021) Modelling the seismic response of a 2-storey URM benchmark case study: comparison among different equivalent frame models. Bull Earthq Eng. https:// doi.org/10.1007/s10518-021-01173-2

Occhipinti G, Caliò I, D’Altri AM et al (2022) Nonlinear finite and discrete element simulations of multistorey masonry walls. Bull Earthq Eng. https://doi.org/10.1007/s10518-021-01233-7

Ottonelli D, Manzini CF, Marano C et al (2021) A comparative study on a complex URM building: part Isensitivity of the seismic response to different modelling options in the equivalent frame models. Bull Earthq Eng. https://doi.org/10.1007/s10518-021-01128-7

Publisher's Note Springer Nature remains neutral with regard to jurisdictional claims in published maps and institutional affiliations. 